\title{
PAPER
}

\section{Available Bandwidth Estimation Method Using End-to-End Delay Increase Rate}

\author{
Masaki Hanada ${ }^{1}$ and Hidehiro Kanemitsu ${ }^{2 *}$ \\ ${ }^{1}$ Department of Information Systems, Tokyo University of Information Sciences \\ 4-1 Onaridai, Wakaba-ku, Chiba-shi, Chiba 265-8501, Japan \\ ${ }^{2}$ Global Education Center, Waseda University, 1-6-1 Nishiwaseda, Shinjuku-ku, Tokyo 169-8050, Japan \\ E-mail:mhanada@rsch.tuis.ac.jp, kanemih@ruri.waseda.jp
}

\begin{abstract}
End-to-end available bandwidth estimation is very important for real-time services such as voice over internet protocol, videoconferencing and peer-to-peer streaming. Several available bandwidth estimation methods such as Pathload, IGI/PTR, pathChirp, Yaz and ASSOLO have been proposed. However, these methods have drawbacks in terms of accuracy of available bandwidth estimation and/or network load performance. In this paper, we present an available bandwidth estimation method comprised of two functions for providing high accurate estimation and low network load performance. One function is the available bandwidth estimation function that directly calculates the available bandwidth using the end-to-end delay increase rate. The other function is the rate adjustment algorithm that adjusts the error between the actual available bandwidth and the available bandwidth calculated using the available bandwidth estimation function. The rate adjustment algorithm of the proposed method is based on that of Pathload because Pathload provides high accuracy in estimating available bandwidth. Finally, we compare the proposed method with Pathload in terms of estimation accuracy and network load performance using computer simulation and demonstrate the effectiveness of the proposed method.
\end{abstract}

Keywords: available bandwidth estimation, probe packet, pathload

\section{Introduction}

In recent years, the rapid growth of broadband networks and performance improvement of desktop personal computers (PC) as well as tablet PCs, has led to the wide use of real-time services such as voice over internet protocol (VoIP) and videoconferencing in addition to web and e-mail services. In order to provide these services to end-users satisfactorily, network carriers should understand the performance of their networks and provide end users with high communication quality. However, the Internet is comprised of distributed autonomous systems that administrate various sections of the overall network. Therefore, understanding end-to-end network performance of the overall network is an important issue. In order to solve this problem, estimation methods for end-to-end network performance have been proposed. Moreover, in [1] and [2], the authors described the importance of available bandwidth estimation for peer-to-peer (P2P) or video streaming services. Therefore, we focus on available bandwidth estimation in this study. Available bandwidth estimation methods such as Pathload

\footnotetext{
${ }^{*}$ Corresponding Author
}

[3], IGI/PTR [4], pathChirp [5], Yaz [6], and ASSOLO [7] have been proposed. These methods involve introducing probe traffic into the network to estimate available bandwidth. Pathload and IGI/PTR increase network load because these methods estimate available bandwidth based on the maximum initial sending rate using a heuristic search procedure. In contrast, PathChirp does not increase network load because it estimates available bandwidth based on the minimum initial sending rate. However, the drawback of this method is the low accuracy of its estimated available bandwidth. Yaz is a calibrated version of Pathload and provides high accurate estimation of available bandwidth. ASSOLO is based on the same principle as pathChirp and provides high accurate and stable estimation of available bandwidth. These methods are described in more detail in Section 2.

In this paper, we present an available bandwidth estimation method for providing high accurate estimation and low network load performance. The proposed method is comprised of two functions. One function is the available bandwidth estimation function that directly calculates the available bandwidth using the end-to-end delay increase rate. Hereinafter, we 
refer to available bandwidth calculated by the available bandwidth estimation function as primary available bandwidth. The other function is the rate adjustment algorithm that reduces the network load required for available bandwidth estimation. The rate adjustment algorithm adjusts the error between the actual available bandwidth and the primary available bandwidth. The rate adjustment algorithm of the proposed method is based on that of Pathload in order to provide high accurate estimation because it has been reported that Pathload provides high accurate results in [8] and [9]. Therefore, the proposed method also provides high accurate estimation. However, the primary available bandwidth calculated using the available bandwidth estimation function can be applied to the initial sending rate of the probe traffic in case of other available bandwidth estimation methods. Using the available bandwidth estimation function, the approximated value of available bandwidth - the primary available bandwidth - can be obtained. Then, by setting the approximated value to the initial sending rate of the probe traffic, it is expected that the network load can be improved because the search range of the rate adjustment algorithm is small. In an evaluation using computer simulation, we compare the proposed method with Pathload because the rate adjustment algorithm of the proposed method is based on that of Pathload. We first compare the primary available bandwidth (i.e. the initial sending rate of the probe traffic of the proposed method) with the initial sending rate of the probe traffic of Pathload. Next, the network load of the proposed method is evaluated with all parameters of the proposed method allocated the same values as those of Pathload (i.e. the estimated available bandwidths of the proposed method and Pathload are almost the same).

The rest of this paper is organized as follows. In Section 2, we introduce works related to this study. In Section 3, we describe Pathload. In Section 4, we present our proposed method including the available bandwidth estimation function and the rate adjustment algorithm. In Section 5, we compare the proposed method with Pathload and evaluate the proposed method in terms of estimation accuracy and network load performance. Finally, Section 6 presents the concluding remarks of this study and potential directions of our future work.

\section{Related Work}

Several available bandwidth estimation methods have been proposed in previous literature. These methods were designed for the same purpose of available bandwidth estimation but were based on different principles. In this section, we introduce the major methods proposed in previous literature.

Pathload is based on self-loading periodic streams and uses the probe rate model (PRM) [12]. It also uses constant bit-rate streams and changes the sending rate during every round based on a binary search. Methods based on PRM send probe traffic at different rates. If the sending rate of probe traffic is higher than the available bandwidth, then the probes are received at a lower rate. The available bandwidth is the maximum rate at which the sending rate matches the receiving rate. Yaz is a calibrated version of Pathload that minimizes overhead. The rate adjustment algorithm of the proposed method is based on Pathload, and details of Pathload are further described in Section 3.

IGI/PTR uses the probe gap model (PGM) [12]. Methods based on PGM send back-to-back probe traffic and estimate available bandwidth based on the dispersion observed at the receiver node. They require a priori knowledge of the capacity of the bottleneck link.

PathChirp reduces probe traffic overhead in comparison to Pathload by sending a train of packets with exponentially decreasing inter-packet spacing that probes a large range of rates. The basic idea of pathChirp is that if the sending rate is less than the available bandwidth, the queuing delay experienced by a probe packet will be zero, and if the sending rate is greater than the available bandwidth, the packet will experience a queuing delay. ASSOLO is another method based on the aforementioned principle, but it features a different probing traffic profile and uses a filter to improve accuracy and stability.

In [8], the authors compared results obtained with several tools on a real testbed for both a constant bit rate $(\mathrm{CBR})$ and Poissonian cross traffic. The authors evaluated the accuracy, intrusiveness and convergence time for the various tools. The authors demonstrated that Pathload and Yaz provided the highest accuracy. In [10], IGI/PTR, pathChirp and Pathload were compared using a testbed equipped with an appropriate measurement station, and in [11], the performance of Pathload, pathChirp, Spruce [12], IGI/PTR and Cprobe were evaluated under various network conditions using computer simulation.

As described above, Pathload, IGI/PTR and pathChirp have been evaluated under various conditions in many previous studies. The rate adjustment algorithm of the proposed method is based on Pathload because Pathload is one of methods that provides high accurate estimation [8] and has been evaluated in many previous studies. In the proposed method, the rate adjustment algorithm of Pathload is enhanced in order to adjust the error between the actual available bandwidth and the available bandwidth calculated using the available bandwidth estimation function.

\section{Pathload}

\subsection{Overview}

Pathload estimates available bandwidth from the maximum sending rate based on a binary search. The 


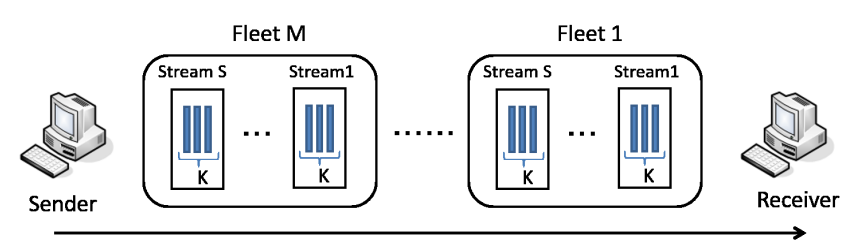

Fig. 1 Structure of probe traffic

structure of the probe traffic is shown in Fig.1. As shown in Fig.1, a stream is composed of $K$ packets, and a fleet is composed of $S$ streams. Pathload introduces probe traffic for the unit of a fleet.

The process flow of Pathload is as follows:

Phase 1: The end-to-end delay between the sender and receiver nodes is measured, then the maximum and minimum sending rates between the sender and receiver nodes are calculated. 100 probe packets are used in this phase [13].

Phase 2: The packet interval is set to a minimum value, then the end-to-end delay from the sender node to the receiver node is measured. Using this measurement, the initial sending rate for the rate adjustment algorithm of Phase 3 is calculated. This initial sending rate is called the average dispersion rate (hereinafter referred to as ADR) and is defined as follows:

$$
A D R=\frac{1}{Q} \sum_{q=1}^{Q} \frac{L^{\max }}{D_{q}}
$$

where $Q$ is the number of probe packets, $L^{\max }$ is the maximum size of probe packets and $D_{q}$ is the end-toend delay of the $q$-th packet. In this phase, $Q$ is set to 100 (i.e. 100 probe packets are used in this phase) [13].

Phase 3: The initial sending rate of a fleet is set as the ADR (Eq.(1)) that is calculated in Phase 2 and the rate adjustment algorithm starts.

\subsection{Rate adjustment algorithm}

This algorithm is executed in Phase $\mathbf{3}$ in Section 3.1. The rate adjustment algorithm is based on a binary search and is presented as Algorithm 1. In Algorithm $1, R^{\text {min }}$ is the highest rate that has been shown to be less than the available bandwidth, while $R^{\max }$ is the lowest rate that has been shown to be greater than the available bandwidth. The sending rate of the $n$-th fleet and the available bandwidth are denoted by $R(n)$ and $A$ respectively.

The initial sending rate of a fleet $R(0)$ is set as the ADR (Eq.(1)) described in Phase 2 of Section 3.1, and $R^{\text {max }}$ and $R^{\text {min }}$ are initially set as 0 . As shown in Algorithm 1, the sending rate $R(n)$ is increased until $R(n) \geq A$ and at the same time, $R^{\text {min }}$ is set as $R(n)$. If $R^{\max }$ is not determined, $R(n+1)=2 \times R(n)$.

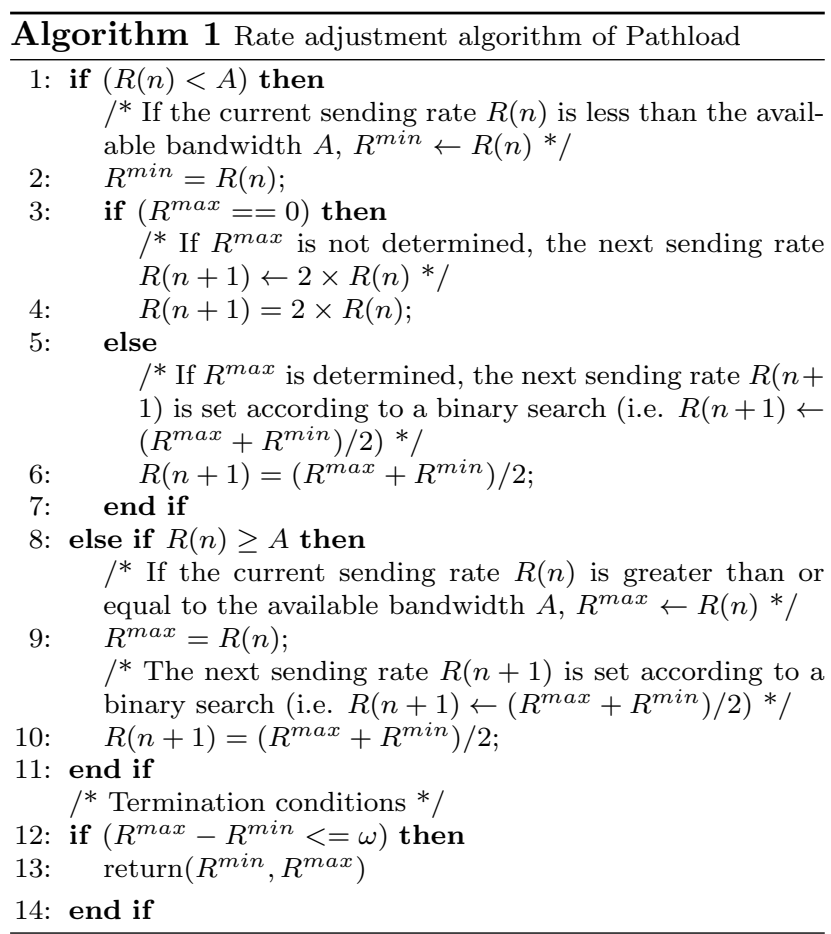

If $R^{\max }$ is determined, $R(n+1)=\left(R^{\max }+R^{\min }\right) / 2$. If $R(n) \geq A$, the sending rate $R(n)$ decreases until $R(n)<A$. At the same time, $R^{\max }$ is set as $R(n)$ and $R(n+1)=\left(R^{\max }+R^{\min }\right) / 2$.

This algorithm continues to send fleets (i.e. probe packets) if $\left[R^{\min }, R^{\max }\right] \leq \omega$ is satisfied. If $\left[R^{\min }, R^{\max }\right] \leq \omega$ is satisfied, the algorithm returns $\left[R^{\min }, R^{\max }\right]$ as an estimation result of the available bandwidth.

\subsection{Detection of increasing trend}

Pathload uses two statistical metrics, i.e. the pairwise comparison test (PCT) and pairwise difference test (PDT), to check if a stream shows an increasing trend. As a pre-processing step, Pathload divides the end-to-end delay-time series $\left\{D_{1}, D_{2}, \ldots, D_{K}\right\}$ into $\Gamma$ $(=\sqrt{K})$ groups. The median value of the end-to-end delay in each group is denoted by $\hat{D}_{i}\left(i=1, \ldots, D_{\Gamma}\right)$.

The PCT metric of a stream $S_{P C T}$ is defined as follows:

$$
S_{P C T}=\frac{\sum_{k=2}^{\Gamma} I\left(\hat{D}_{k}-\hat{D}_{k-1}\right)}{\Gamma-1}
$$

where $I(X)$ is one if $X$ holds and zero otherwise. The PCT measures the fraction of the consecutive end-toend delay pairs that are increasing. If there is a strong increasing trend, the result of the PCT approaches one. In the case of the Pathload tool [13], the PCT metric reports an "increasing trend" if $S_{P C T}>0.605$ (hereinafter referred to as $P I_{P C T}$ ), a "non-increasing trend" if $S_{P C T}<0.495$ (hereinafter referred to as $P N_{P C T}$ ), and an "ambiguous trend" otherwise. 
The PDT metric of a stream $S_{P D T}$ is defined as follows:

$$
S_{P D T}=\frac{\hat{D}_{\Gamma}-\hat{D}_{1}}{\sum_{k=2}^{\Gamma}\left|\hat{D}_{k}-\hat{D}_{k-1}\right|}
$$

The PDT quantifies how strong the start-to-end endto-end delay variation is. If there is a strong increasing trend, $S_{P D T}$ approaches one. In the case of the Pathload tool [13], the PDT metric reports an "increasing trend" if $S_{P D T}>0.44$ (hereinafter referred to as $P I_{P D T}$ ), a "non-increasing trend" if $S_{P D T}<$ 0.36 (hereinafter referred to as $P N_{P D T}$ ), and an "ambiguous trend" otherwise.

When one of the PCT and PDT metrics reports an increasing trend, while the other reports either an increasing trend or an ambiguous trend, the stream is characterized as Type-I (indicating an increasing trend). Similarly, when one metric reports a nonincreasing trend, while the other reports either a nonincreasing trend or an ambiguous trend, the stream is characterized as Type- $\mathrm{N}$ (indicating a non-increasing trend). If both metrics report an ambiguous trend, or when one reports an increasing trend and the other reports a non-increasing trend, the stream is discarded.

After all $N$ streams of a fleet are received, the receiver node determines whether $R>A$. If a large fraction $f$ of $N$ streams in a fleet are of Type-I, the entire fleet exhibits an increasing trend (i.e. $R>A$ ). Similarly, if a fraction $f$ of $N$ streams are of Type$\mathrm{N}$, the fleet does not exhibit an increasing trend (i.e. $R<A)$.

\section{Proposed Method}

In this section, we first describe the basic policy of the proposed method. We then describe the process flow of the proposed method and the available bandwidth estimation function for calculating the primary available bandwidth. Finally, we describe the rate adjustment algorithm for searching for the available bandwidth within a small search range.

\subsection{Basic policy}

If the number of relay nodes, available bandwidth of the relay nodes and link capacity between the relay nodes are given, the available bandwidth can be accurately estimated. However, it is difficult to obtain this information at the sender and receiver nodes because general available bandwidth estimation methods such as Pathload, IGI/PTR and pathChirp use functions provided by the application layer.

In the first step of the proposed method, we set the sending rate of a fleet $(R(0))$ as the link capacity of the bottleneck link and measure the end-to-end delay increase rate between the sender and receiver nodes. We then apply the measured end-to-end delay increase rate to the available bandwidth estimation function, which can be used to directly calculate the available bandwidth. The available bandwidth estimation function is described in Section 4.3. This function is one of the features of the proposed method for reducing the network load required for available bandwidth estimation (i.e. reduction in the number of probe packets). Using the available bandwidth estimation function, it is expected that the approximated value of available bandwidth, i.e. the primary available bandwidth, can be obtained. However, there is a possibility that the primary available bandwidth calculated using the available bandwidth estimation function includes an estimation error. Thus, the estimation error between the actual available bandwidth and the primary available bandwidth is adjusted by the rate adjustment algorithm of the proposed method. This algorithm is described in Section $\mathbf{4 . 4}$

\subsection{Overview}

The process flow of the proposed method is as follows: Phase 1: The end-to-end delay between the sender and receiver nodes is measured and the maximum and minimum sending rates between the sender and receiver nodes are calculated. Moreover, the link capacity of the bottleneck link $C_{B}$ is calculated using the packet-pair method [14]. In this phase, 100 probe packets are used, which is similar to the number of probe packets used in Pathload.

Phase 2: The sending rate is set as the link capacity of the bottleneck link $C_{B}$ and the end-to-end delay increase rate from the sender node to the receiver node is measured. The end-to-end delay increase rate is calculated using the following procedure. First, the sending rate is set as the aforementioned link capacity of the bottleneck link. The sender then inserts the output time of each packet into the packet header and sends the packet to the receiver node. The receiver node receives the packet and calculates the time difference (i.e. the end-to-end delay). Finally, the receiver obtains the output time series $V_{q}(q=1, \ldots, Q)$ and end-to-end delay series $D_{q}(q=1, \ldots, Q)$. From these times, the end-to-end delay increase rate $E I^{m s t}$ is calculated using the least-squares method.

$$
E I^{m s t}=\frac{Q \sum_{q=1}^{Q} V_{q} D_{q}-\sum_{q=1}^{Q} V_{q} \sum_{q=1}^{Q} D_{q}}{Q \sum_{q=1}^{Q} V_{q}^{2}-\left(\sum_{q=1}^{Q} V_{q}\right)^{2}}
$$

In this phase, 100 probe packets are used, which is similar to the number of probe packets used in Pathload (i.e. $Q=100$ ).

Applying the measured end-to-end delay increase rate $E I^{m s t}$ to the available bandwidth estimation function, the primary available bandwidth can be calculated. The available bandwidth estimation function is 


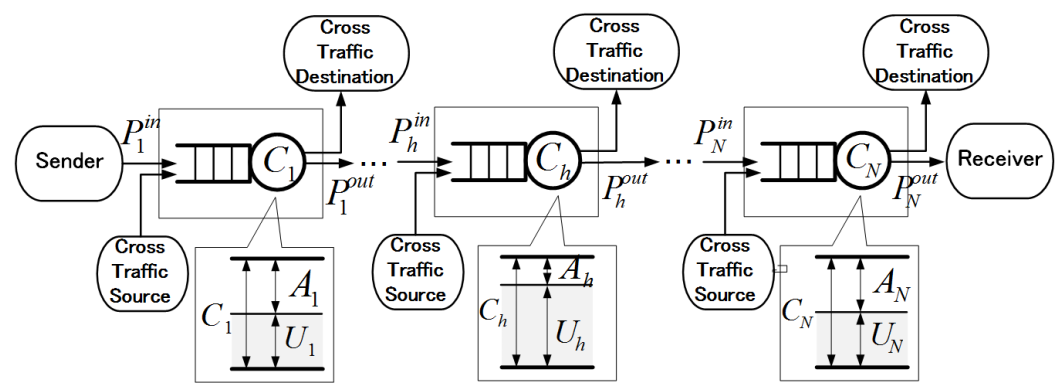

Fig. 2 Assumed network model

described in Section 4.3.

Phase 3: The initial sending rate of a fleet is set as the primary available bandwidth that is calculated using the available bandwidth estimation function of Phase $\mathbf{2}$, and the rate adjustment algorithm starts.

The difference between Phase 1 of Pathload and that of the proposed method is the calculation of the link capacity of the bottleneck link. The link capacity of the bottleneck link $C_{B}$ can be calculated using the packet-pair method [14] without extra probe packets in Phase 1. The difference in Phase $\mathbf{2}$ is that the proposed method calculates the primary available bandwidth, while Pathload calculates the ADR (Eq.(1)). It is expected that the primary available bandwidth obtained using the available bandwidth estimation function will be more accurate than the ADR (Eq.(1)). The difference in Phase 3 is that the proposed method can search for the available bandwidth within a small search range using the primary available bandwidth, while Pathload searches for the available bandwidth within a large search range.

\subsection{Available bandwidth estimation function}

This function is used in Phase 2 in Section 4.2 and it directly calculates the available bandwidth using the end-to-end delay increase rate. In this section, we first derive the end-to-end delay increase rate theoretically. Next, we describe a formula that can be used to derive the primary available bandwidth from the end-to-end delay increase rate. Hereinafter, we refer to this formula as the available bandwidth estimation formula.

\subsubsection{Derivation of end-to-end delay increase rate}

We assume a network model (Fig.2) in which the probe traffic goes through $N$ hops and the cross traffic crosses each node.

If the number of relay nodes in a route, available bandwidth of a relay node and link capacity between the relay nodes are given, we can calculate the endto-end delay increase rate. Next, we explain the calculation of the end-to-end delay increase rate using information such as the number of relay nodes in a route.

Let us denote the input rate at a relay node $h$ by $P_{h}^{i n}$, the output rate at a relay node $h$ by $P_{h}^{\text {out }}$, the link capacity at a relay node $h$ by $C_{h}$, the available bandwidth at a relay node $h$ by $A_{h}$ and the input rate of the cross traffic (i.e. network-bandwidth usage) at a relay node $h$ by $U_{h}$. The input rate at the relay node $h\left(P_{h}^{\text {out }}\right)$ is then defined as follows:

$$
P_{h}^{\text {out }}=P_{h+1}^{i n}= \begin{cases}C_{h} \frac{P_{h}^{i n}}{P_{h}^{i n}+U_{h}}, & P_{h}^{i n}>A_{h} \\ P_{h}^{i n}, & P_{h}^{i n} \leq A_{h}\end{cases}
$$

Here, the output rate at the relay node $h\left(P_{h}^{\text {out }}\right)$ is the same as the input rate at the relay node $h+1$ $\left(P_{h+1}^{i n}\right)$. If $P_{h}^{i n} \leq A_{h}$ is satisfied, no delay occurs at the relay node $h$.

The delay increase rate at the relay node $h\left(I_{h}\right)$ is defined as follows:

$$
I_{h}= \begin{cases}\frac{P_{h}^{i n}+U_{h}-C_{h}}{P_{h}^{i n}}, & P_{h}^{i n}>A_{h} \\ 0, & P_{h}^{i n} \leq A_{h}\end{cases}
$$

From Eq.(6), it can be observed that the delay increase rate at the relay node $h\left(I_{h}\right)$ is the same as the rate that exceeds $P_{h}^{i n}$. That is, the packets are queued at the rate $I_{h}>0$ at the relay node $h$ if $P_{h}^{i n}>A_{h}$ is satisfied.

When the number of relay nodes in a route $(N)$ is given, the end-to-end delay increase rate $E I$ can be defined as follows based on Eq.(6):

$$
E I=\sum_{h=1}^{N} I_{h}
$$

\subsubsection{Available bandwidth estimation formula}

In this section, we first calculate the maximum and minimum end-to-end delay increase rate under the condition that all the link capacities are the same in a route. When the available bandwidth is $A$, the case in which the maximum end-to-end delay increase rate is achieved is shown in Fig. 3 and the case in which the minimum end-to-end delay increase rate is achieved is shown in Fig.4. 
Fig. 3 shows the case in which the available bandwidth $A_{h}$ for all the relay nodes $h$ is equal to the available bandwidth $A$. In this case, the probe packets experience a delay at all the relay nodes in the route.

From Fig.3, it can be observed that the link capacities at all the relay nodes are the same (i.e. $C_{h}=C_{B}$ $(h=1, \ldots, H))$ and the input rate of cross traffic (i.e. network bandwidth usage) at all the relay nodes is the same (i.e. $\left.U_{h}=U(h=1, \ldots, H)\right)$. Then, using Eqs.(5) and (6), $P_{h}^{\text {out }}$ and $I_{h}$ are rewritten as follows:

$$
\begin{aligned}
P_{h}^{\text {out }} & =P_{h+1}^{\text {in }}=C_{B} \frac{P_{h}^{i n}}{P_{h}^{i n}+U} \\
I_{h} & =\frac{P_{h}^{i n}+U-C_{B}}{P_{h}^{i n}}
\end{aligned}
$$

From Phase 1 in Section 4.2, $P_{1}^{i n}=C_{B}$ is satisfied because the sending rate is set as the aforementioned link capacity of the bottleneck link. Thus, $U=C_{B}-A=P_{1}^{i n}-A$ is satisfied, and Eqs.(8) and (9) are rewritten as follows:

$$
\begin{aligned}
P_{h}^{\text {out }} & =P_{h+1}^{i n}=P_{1}^{i n} \frac{P_{h}^{i n}}{P_{h}^{i n}+P_{1}^{i n}-A} \\
I_{h} & =\frac{P_{h}^{i n}+P_{1}^{i n}-A-P_{1}^{i n}}{P_{h}^{i n}}=\frac{P_{h}^{i n}-A}{P_{h}^{i n}}
\end{aligned}
$$

Based on Eq.(11), the maximum end-to-end delay increase rate $E I_{\max }$ is defined as follows:

$$
E I_{\text {max }}=\sum_{h=1}^{H}\left(\frac{P_{h}^{i n}-A}{P_{h}^{i n}}\right)
$$

where $H$ is the system parameter because the receiver node does not know the number of relay nodes.

Similarly, the minimum end-to-end delay increase rate is achieved as shown in Fig.4. Fig.4 shows the case that the available bandwidth $A_{h}$ for a relay node $h$ is equal to the available bandwidth $A$. In this case, the probe packets only experience a delay at the relay node (i.e. relay node 1 ) in the route.

The end-to-end delay increase rate $E I$ is defined as follows:

$$
E I=I_{1}=\frac{P_{1}^{i n}+P_{1}^{i n}-A-P_{1}^{i n}}{P_{1}^{i n}}=\frac{P_{1}^{i n}-A}{P_{1}^{i n}}
$$

Because the delay does not occur at the other relay nodes except for the relay node 1 , the minimum end-toend delay increase rate $E I_{\min }$ can be defined as follows:

$$
E I_{\text {min }}=I_{1}=\frac{P_{1}^{i n}-A}{P_{1}^{i n}}
$$

In Phase 2 in Section $\mathbf{4 . 2}$, the measured end-toend delay increase rate $E I^{m s t}$ is obtained. Given the measured end-to-end delay increase rate $E I^{m s t}$, the estimated maximum and minimum available bandwidths $A_{\max }$ and $A_{\min }$ are defined as follows:

$$
\begin{aligned}
& A_{\text {max }}=\left\{A: E I^{m s t}=\sum_{h=1}^{H}\left(\frac{P_{h}^{i n}-A}{P_{1}^{i n}}\right)\right\} \\
& A_{\text {min }}=\left\{A: E I^{m s t}=\frac{P_{1}^{i n}-A}{P_{1}^{i n}}\right\}
\end{aligned}
$$

Based on Eqs.(15) and (16), the primary available bandwidth $A^{1 s t}$ in Phase 2 in Section 4.2 can be defined as follows:

$$
A^{1 s t}=w A_{\max }+(1-w) A_{\min }
$$

where $w$ is the system parameter.

\subsubsection{Example of $E I_{\min }$ and $E I_{\max }$}

In this section, we present an example of $E I_{\min }$ and $E I_{\max }$. In this example, we assume that $U=75 \mathrm{Mbps}$ $\left(U_{1}=U_{2}=\ldots=U_{H}=U\right), P_{1}^{i n}=100 \operatorname{Mbps}\left(P_{1}^{i n}=\right.$ $C_{B}$ ) and the parameter $H=20$. From $A=C_{B}-U$, we obtain $A=25 \mathrm{Mbps}$.

On substituting $A=25 \mathrm{Mbps}$ and $P_{1}^{i n}=100 \mathrm{Mbps}$ into Eqs.(10) and (11), we obtain

$$
\begin{aligned}
P_{1}^{\text {out }} & =P_{2}^{\text {in }}=P_{1}^{i n} \frac{P_{1}^{i n}}{P_{1}^{i n}+P_{1}^{i n}-A} \\
& =\frac{100 \times 100}{100+100-25} \\
& =57.142857(\mathrm{Mbps}), \\
I_{1} & =\frac{P_{h}^{i n}-A}{P_{h}^{i n}} \\
& =\frac{100-25}{100}=0.7500
\end{aligned}
$$

Similarly, on substituting $A=25 \mathrm{Mbps}, P_{1}^{\text {in }}=100$ Mbps, and $P_{2}^{i n}=57.142857 \mathrm{Mbps}$ into Eqs.(10) and (11), we obtain

$$
\begin{aligned}
P_{2}^{\text {out }} & =P_{1}^{\text {in }} \frac{P_{2}^{i n}}{P_{2}^{i n}+P_{1}^{i n}-A} \\
& =\frac{100 \times 57.142857}{57.142857+100-25} \\
& =43.243243(\mathrm{Mbps}), \\
I_{2} & =\frac{P_{h}^{i n}-A}{P_{h}^{i n}} \\
& =\frac{57.142857-25}{57.142857}=0.5625
\end{aligned}
$$

After repeating the substitution until $H=20$, we obtain the results shown in Table 1. From Table 1, we obtain the following equations.

$$
\begin{aligned}
& E I_{\text {max }}=\sum_{h=1}^{20}\left(\frac{P_{h}^{i n}-A}{P_{h}^{i n}}\right)=2.9905 \\
& E I_{\text {min }}=I_{1}=\frac{P_{1}^{i n}-A}{P_{1}^{i n}}=0.7500
\end{aligned}
$$




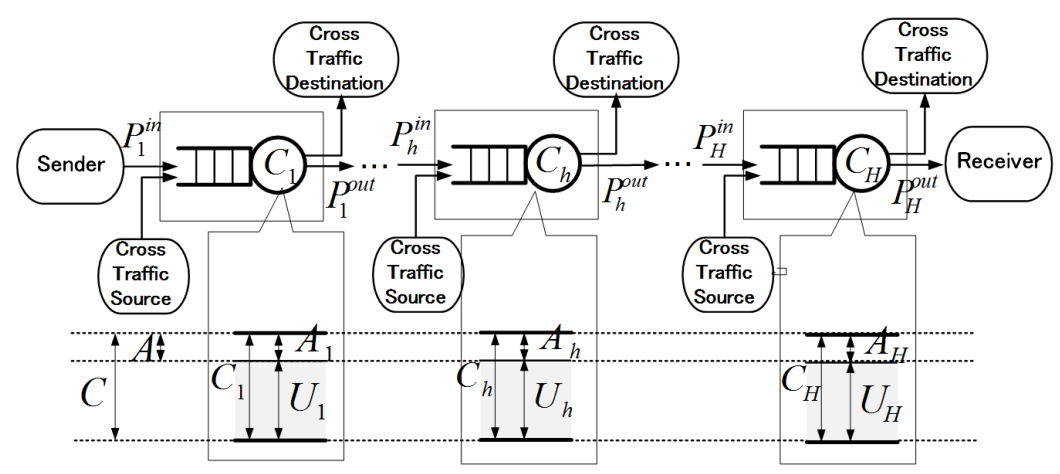

Fig. 3 Case in which maximum end-to-end delay increase rate is achieved

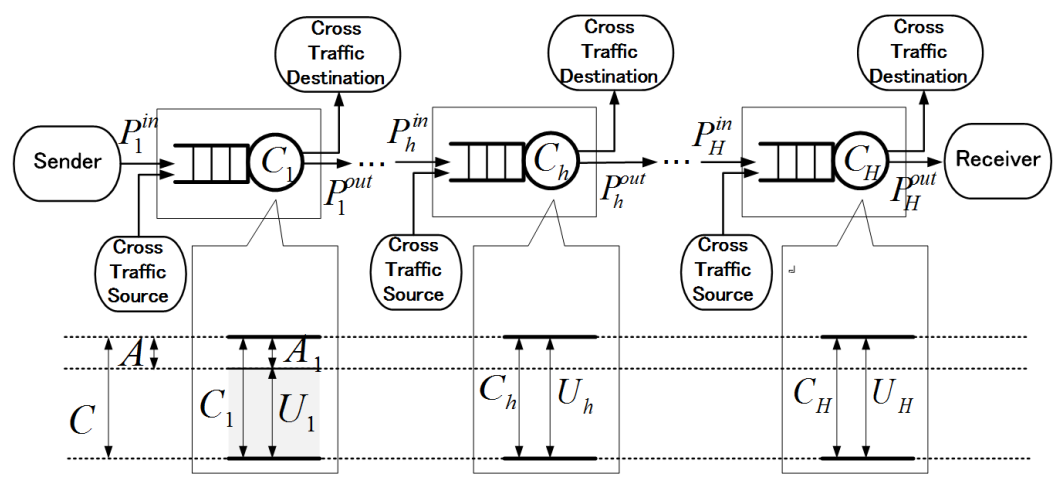

Fig. 4 Case in which minimum end-to-end delay increase rate is achieved

\subsection{Rate adjustment algorithm}

The rate adjustment algorithm of the proposed method is based on that of Pathload in order to provide high accurate estimation because it has been reported that Pathload provides high accurate results in [8] and [9]. Therefore, the proposed method can also provide high accurate estimation similar to Pathload. However, there is a possibility that the rate adjustment algorithm of Pathload needs high network load in estimating available bandwidth. This is because it needs to search for the available bandwidth within a large search range since the initial sending rate (i.e. ADR (Eq.(1))) for the rate adjustment algorithm of Pathload does not have enough estimation accuracy. To solve this problem, the rate adjustment algorithm of the proposed method shortens the search range using the primary available bandwidth because it is expected that the primary available bandwidth is more accurate than the ADR (Eq.(1)). As a result, it is expected that the proposed method can simultaneously provide high accurate estimation and low network load performance.

The rate adjustment algorithm is shown in Algorithm 2. As described in Section 3.2, in Algorithm $\mathbf{2}, R^{\text {min }}$ is the highest rate that has been shown to be less than the available bandwidth, while $R^{\max }$ is the lowest rate that has been shown to be greater than the available bandwidth. The sending rate of the $n$-th fleet and the available bandwidth are denoted by $R(n)$ and $A$ respectively. In addition, we introduce a system parameter $\Delta$ because the rate adjustment algorithm of the proposed method searches for the available bandwidth within a range near the primary available bandwidth. The basic concept of the rate adjustment algorithm is to search for the available bandwidth within the range between $A^{1 s t}-\Delta$ and $A^{1 s t}+\Delta$.

The initial sending rate of a fleet $R(0)$ is set as the primary available bandwidth $A^{1 s t}$ that is calculated using the available bandwidth estimation function (Phase 2 in Section 4.2), and $R^{\max }$ and $R^{\text {min }}$ are initially set as 0 . The main difference between the rate adjustment algorithm of Pathload and the proposed method is the search range (i.e. $R(n+1)=R(n)+\Delta$ (Line 4$)$ and $R(n+1)=R(n)-\Delta$ (Line 11) of Algorithm 2). By using this search range for the rate adjustment, it is expected that the network load can be improved as compared with that of Pathload.

As shown in Algorithm 2, the sending rate $R(n)$ is increased until $R(n)>A$, and at the same time, $R^{\text {min }}$ is set to $R(n)$. If $R^{\max }$ is not determined, $R(n+1)=$ $R(n)+\Delta$, while $R(n+1)=2 \times R(n)$ in Pathload. We will obtain the 2 nd sending rate of a fleet $R(1)$ as 
Table 1 Results of $P_{h}^{\text {out }}\left(\right.$ i.e. $\left.P_{h+1}^{i n}\right)(\mathrm{Mbps})$ and $I_{h}$

\begin{tabular}{|c|c|c|c|c|c|c|c|c|c|c|}
\hline$h$ & 1 & 2 & 3 & 4 & 5 & 6 & 7 & 8 & 9 & 10 \\
\hline$P_{h}^{\text {out }}$ & 100.000000 & 57.142857 & 43.243243 & 36.571429 & 32.778489 & 30.412830 & 28.851166 & 27.781263 & 27.029502 & 26.491849 \\
\hline$I_{h}$ & 0.7500 & 0.5625 & 0.4219 & 0.3164 & 0.2373 & 0.1780 & 0.1335 & 0.1001 & 0.07508 & 0.05631 \\
\hline \hline$h$ & 11 & 12 & 13 & 14 & 15 & 16 & 17 & 18 & 19 & 20 \\
\hline$P_{h}^{\text {out }}$ & 26.102440 & 25.817814 & 25.608385 & 25.453530 & 25.338612 & 25.253102 & 25.189347 & 25.141742 & 25.106156 & 25.079533 \\
\hline$I_{h}$ & 0.04224 & 0.03168 & 0.02376 & 0.01782 & 0.01336 & 0.0100 & 0.0075 & 0.0056 & 0.0042 & 0.0032 \\
\hline
\end{tabular}

an example. If $R(0)<A$ (i.e. $A^{1 s t}<A$ ) and $R^{\max }$ is not determined, $R(1)=A^{1 s t}+\Delta$. This sending rate $R(1)=A^{1 s t}+\Delta$ means that this algorithm searches for $R^{\max }$ within a range close to $A^{1 s t}+\Delta$ as next step. If $R^{\text {max }}$ is determined, $R(n+1)=\left(R^{\max }+R^{\text {min }}\right) / 2$. If $R(n) \geq A$, the sending rate $R(n)$ is decreased until $R(n)<A$ and at the same time, $R^{\max }$ is set as $R(n) . \quad R(n+1)=R(n)-\Delta$ if $R^{m i n}=0$, and $R(n+1)=\left(R^{\max }+R^{\text {min }}\right) / 2$ otherwise. Similarly, we will obtain the 2 nd sending rate of a fleet $R(1)$ as an example. If $R(0) \geq A$ (i.e. $A^{1 s t} \geq A$ ) and $R^{\text {min }}$ is not determined, $R(1)=A^{1 s t}-\Delta$. This sending rate $R(1)=A^{1 s t}-\Delta$ means that this algorithm searches for $R^{\text {min }}$ within a range close to $A^{1 s t}-\Delta$ as next step. This algorithm continues to send fleets (i.e. probe packets) if $\left[R^{\min }, R^{\max }\right] \leq \omega$ is satisfied. If $\left[R^{\text {min }}, R^{\max }\right] \leq \omega$ is satisfied, the algorithm returns $\left[R^{\min }, R^{\max }\right]$ as an estimation result of the available bandwidth.

This rate adjustment algorithm also uses the PCT and PDT metrics to check if a stream shows an increasing trend and uses the termination conditions, which is similar to the process of Pathload. Therefore, when the parameters of the proposed method are allocated the same values as those of Pathload, the estimated available bandwidth of the proposed method is almost the same as that of Pathload.

\section{Evaluation}

In this section, we first compare the initial sending rates of the probe traffic of the proposed method with that of Pathload because the initial sending rate has a strong influence on the network load performance. The initial sending rates of the proposed method and Pathload are the primary available bandwidth estimation $\left(A^{1 s t}\right)$ (Eq.(17)) and ADR (Eq.(1)), respectively. Next, we compare the network load of the proposed method with that of Pathload using computer simulation under the condition that the estimation accuracy of the available bandwidths of Pathload and the proposed method is the same. In this simulation, we set all the parameters of the proposed method to be the same as those of Pathload in order to match the accuracy of the estimated available bandwidths of both methods.

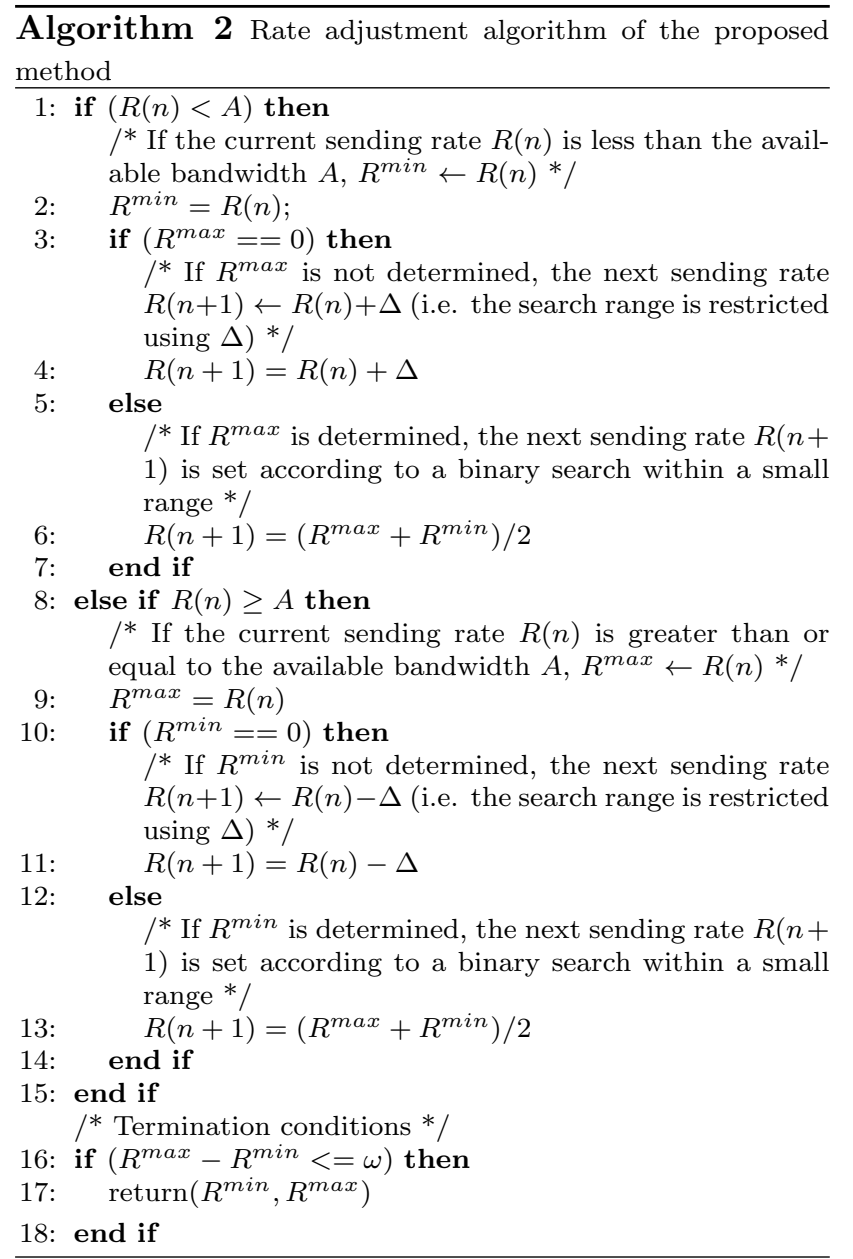

\subsection{Simulation conditions}

The assumed network model in which the probe traffic passes through $N$ relay nodes in the network is shown in Fig.5. The number of relay nodes is 10 (i.e. $N$ $=10)$. The probe traffic is sent from the Sender to the Receiver, and the available bandwidth is then estimated. The cross traffic at the sending rate $U_{h}$ is introduced at the relay node $h$. The patterns of the sending rate $U_{h}$ of the cross traffic can be observed in Tables 3 to 8 . Tables 3,4 and 5 show the patterns for which the available bandwidth $A$ is $25 \mathrm{Mbps}$. For example, in Case 1 of Table 3, the cross traffic at the sending rate of $75 \mathrm{Mbps}$ is introduced at relay node 1 and the cross traffic is not introduced at relay nodes 2-10. Similarly, in Case 2 of Table 3, the cross traf- 


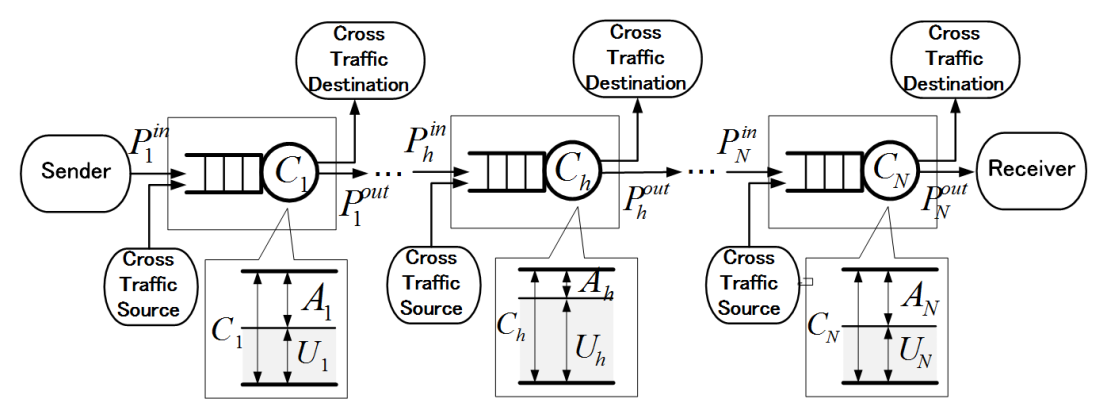

Fig. 5 Simulation network model

fic at the sending rate of $75 \mathrm{Mbps}$ is independently introduced at relay nodes 1 and 2 , and the cross traffic is not introduced at relay nodes $3-10$. In Table 4, the cross traffic at the sending rate of $75 \mathrm{Mbps}$ is introduced at a relay node. For example, in Case 4 of Table 4 , the cross traffic at the sending rate of $75 \mathrm{Mbps}$ is only introduced at relay node 4 and the cross traffic is not introduced at relay nodes $1-3$ and 5-10. In Table 5 , the cross traffic at the sending rate of $75 \mathrm{Mbps}$ is introduced at a relay node, and the cross traffic at half the sending rate $75 / 2=37.5 \mathrm{Mbps}$ is introduced at the other relay nodes. For example, in Case 4 of Table 5 , the cross traffic at the sending rate of $75 \mathrm{Mbps}$ is only introduced at relay node 4 and the cross traffic at the sending rate $37.5 \mathrm{Mbps}$ is introduced at the relay nodes $1-3$ and $5-7$. In addition, the cross traffic is not introduced at the relay nodes $8-10$. Tables 6,7 , and 8 show the patterns for which the available bandwidth $A$ is 75 Mbps.

The simulation parameters are listed in Table 2 . The packet size of the probe and cross traffic is 1000 bytes, and the link capacity of all the relay nodes is $100 \mathrm{Mbps}$. The packet interval of the cross traffic is based on an exponential distribution. $\Delta$ (Lines 4 and 11) of Algorithm 2 is set as $0.25 \times A^{1 s t}$ (i.e. the primary available bandwidth). The parameter of the number of relay nodes $H$ of Eq.(15) is set as 20 .

\subsection{Simulation results}

We first evaluate the primary available bandwidth $\left(A^{1 s t}\right)$ (Eq.(17)). The simulation results in terms of the primary available bandwidth $\left(A^{1 s t}\right)$ (Eq.(17)) and ADR (Eq.(1)) for each pattern are shown in Figs.6, 7, $8,9,10$ and 11 . We refer to the available bandwidth as avail-bw in all the figures. In addition, in Figs.6, 7, 8, 9, 10 and 11, the estimated available bandwidths of the proposed method and Pathload are denoted by the black circles and black squares, respectively. The estimated available bandwidths of the proposed method and Pathload are almost the same because the parameters used in the proposed method and Pathload are set such that they are the same.

The differences between the estimated available bandwidth and ADR in the case of Pathload and between the estimated available bandwidth and the primary available bandwidth $\left(A^{1 s t}\right)$ in the case of the proposed method are shown in Figs.12, 13, 14, 15, 16 and 17. In Figs.12, 13, 14, 15, 16 and 17, all the differences between the estimated available bandwidth and the primary available bandwidth $\left(A^{1 s t}\right)$ in the case of the proposed method are smaller than in the case of Pathload. Based on these results, the primary available bandwidth $\left(A^{1 s t}\right)$ is more accurate than the ADR for all the patterns. In particular, the primary available bandwidth $\left(A^{1 s t}\right)$ is almost the same as the estimated available bandwidth when the available bandwidth is $75 \mathrm{Mbps}$ (Figs.15, 16 and 17). This is because the sending rate of the cross traffic is low (i.e. $25 \mathrm{Mpbs}$ ) and the cross traffic has little impact on the calculation of the primary available bandwidth obtained using the available bandwidth estimation function.

In Figs.12, 14, 15 and 17, the larger the number of relay nodes at which the cross traffic is introduced, the more accurate the primary available bandwidths $\left(A^{1 s t}\right)$ are. This is because the output rate of the probe traffic approaches the available bandwidth whenever the probe traffic passes through a relay node, which can be observed from Eq.(5) and Table 1. In contrast, in Figs.13 and 16, the primary available bandwidth $\left(A^{1 s t}\right)$ is almost constant because the number of relay nodes at which the cross traffic is introduced is 1 .

Next, we evaluate the network load required for the available bandwidth estimation. The simulation results in terms of the number of fleets of the rate adjustment algorithm for each pattern are shown in Figs.18, 19, 20, 21, 22 and 23. Essentially, if the initial sending rate of the rate adjustment algorithm is almost the same as the estimated available bandwidth, the number of fleets is small. In Figs.18, 19, 20, 21, 22 and 23, the number of fleets of the proposed method is smaller than that of Pathload except in three cases (i.e. Cases 3, 4 and 5 in Fig.19). This is because the differences between the estimated available bandwidth and the primary available bandwidth $\left(A^{1 s t}\right)$ in the case of the proposed method are smaller than in the case of Pathload as shown in Figs.12, 13, 14, 15, 16 and 17. As a result, 
Table 2 Parameters

\begin{tabular}{|c|c|c|c|c|c|c|c|}
\hline$S$ (streams) & $K$ (packets) & $f$ & $\omega$ (Mbps) & $P I_{P C T}$ & $P N_{P C T}$ & $P I_{P D T}$ & $P N_{P D T}$ \\
\hline 12 & 100 & 0.3 & 2 & 0.605 & 0.495 & 0.44 & 0.36 \\
\hline
\end{tabular}

Table 3 Parameters of cross traffic (Pattern 1; $A=25$ Mbps)

\begin{tabular}{|c|c|c|c|c|c|c|c|c|c|c|}
\hline \multirow{2}{*}{$\begin{array}{c}\text { Case } \\
\#\end{array}$} & \multicolumn{10}{|c|}{ Sending rate of cross traffic (Mbps) } \\
\cline { 2 - 13 } & 1 & 2 & 3 & 4 & 5 & 6 & 7 & 8 & 9 & 10 \\
\hline 1 & 75 & 0 & 0 & 0 & 0 & 0 & 0 & 0 & 0 & 0 \\
\hline 2 & 75 & 75 & 0 & 0 & 0 & 0 & 0 & 0 & 0 & 0 \\
\hline 3 & 75 & 75 & 75 & 75 & 0 & 0 & 0 & 0 & 0 & 0 \\
\hline 4 & 75 & 75 & 75 & 75 & 75 & 75 & 75 & 0 & 0 & 0 \\
\hline 5 & 75 & 75 & 75 & 75 & 75 & 75 & 75 & 75 & 75 & 75 \\
\hline
\end{tabular}

Table 5 Parameters of cross traffic (Pattern 3; $A=25$ Mbps)

\begin{tabular}{|c|c|c|c|c|c|c|c|c|c|c|}
\hline Case & \multicolumn{10}{|c|}{ Sending rate of cross traffic (Mbps) } \\
\cline { 2 - 13 }$\#$ & \multicolumn{10}{|c|}{ Relay node $(h)$} \\
\cline { 2 - 12 } & 1 & 2 & 3 & 4 & 5 & 6 & 7 & 8 & 9 & 10 \\
\hline 1 & 75 & 0 & 0 & 0 & 0 & 0 & 0 & 0 & 0 & 0 \\
\hline 2 & 75 & 37.5 & 0 & 0 & 0 & 0 & 0 & 0 & 0 & 0 \\
\hline 3 & 37.5 & 75 & 37.5 & 37.5 & 0 & 0 & 0 & 0 & 0 & 0 \\
\hline 4 & 37.5 & 37.5 & 37.5 & 75 & 37.5 & 37.5 & 37.5 & 0 & 0 & 0 \\
\hline 5 & 37.5 & 37.5 & 37.5 & 37.5 & 75 & 37.5 & 37.5 & 37.5 & 37.5 & 37.5 \\
\hline
\end{tabular}

Table 7 Parameters of cross traffic (Pattern 5; $A=75$ Mbps)

\begin{tabular}{|c|c|c|c|c|c|c|c|c|c|c|}
\hline \multirow{2}{*}{$\begin{array}{c}\text { Case } \\
\#\end{array}$} & \multicolumn{10}{|c|}{ Sending rate of cross traffic (Mbps) } \\
\cline { 2 - 12 } & 1 & 2 & 3 & 4 & 5 & 6 & 7 & 8 & 9 & 10 \\
\hline 1 & 25 & 0 & 0 & 0 & 0 & 0 & 0 & 0 & 0 & 0 \\
\hline 2 & 25 & 0 & 0 & 0 & 0 & 0 & 0 & 0 & 0 & 0 \\
\hline 3 & 0 & 25 & 0 & 0 & 0 & 0 & 0 & 0 & 0 & 0 \\
\hline 4 & 0 & 0 & 0 & 25 & 0 & 0 & 0 & 0 & 0 & 0 \\
\hline 5 & 0 & 0 & 0 & 0 & 25 & 0 & 0 & 0 & 0 & 0 \\
\hline
\end{tabular}

the rate adjustment algorithm of the proposed method can search for the available bandwidth within a small search range (i.e. $R(n+1)=R(n)+\Delta$ (Line 4) and $R(n+1)=R(n)-\Delta$ (Line 11) of Algorithm 2). In particular, the difference between the number of fleets of the proposed method and Pathload is large when the available bandwidth is $75 \mathrm{Mbps}$ (Figs.21, 22 and 23 ) because the primary available bandwidth $\left(A^{1 s t}\right)$ is almost the same as the estimated available bandwidth when the available bandwidth is 75 Mbps (Figs.15, 16 and 17).

In contrast, the number of fleets of the proposed method is larger than that of Pathload in Cases 3, 4 and 5 in Fig.19. In these cases, there is a great difference between the primary available bandwidth $\left(A^{1 s t}\right)$ and the estimated available bandwidths even though the differences between the primary available bandwidth $\left(A^{1 s t}\right)$ and the estimated available bandwidth in the case of the proposed method are smaller than in the case of Pathload as shown in Cases 3,4 and 5 in Figs. 7 and 13. In such cases, the binary search within a large search range used in the rate adjustment al-
Table 4 Parameters of cross traffic (Pattern 2; $A=25$ Mbps)

\begin{tabular}{|c|c|c|c|c|c|c|c|c|c|c|}
\hline \multirow{2}{*}{$\begin{array}{c}\text { Case } \\
\#\end{array}$} & \multicolumn{10}{|c|}{ Sending rate of cross traffic (Mbps) } \\
\cline { 2 - 12 } & 1 & 2 & 3 & 4 & 5 & 6 & 7 & 8 & 9 & 10 \\
\hline 1 & 75 & 0 & 0 & 0 & 0 & 0 & 0 & 0 & 0 & 0 \\
\hline 2 & 75 & 0 & 0 & 0 & 0 & 0 & 0 & 0 & 0 & 0 \\
\hline 3 & 0 & 75 & 0 & 0 & 0 & 0 & 0 & 0 & 0 & 0 \\
\hline 4 & 0 & 0 & 0 & 75 & 0 & 0 & 0 & 0 & 0 & 0 \\
\hline 5 & 0 & 0 & 0 & 0 & 75 & 0 & 0 & 0 & 0 & 0 \\
\hline
\end{tabular}

Table 6 Parameters of cross traffic (Pattern 4; $A=75$ Mbps)

\begin{tabular}{|c|c|c|c|c|c|c|c|c|c|c|}
\hline \multirow{2}{*}{$\begin{array}{c}\text { Case } \\
\#\end{array}$} & \multicolumn{10}{|c|}{ Sending rate of cross traffic (Mbps) } \\
\cline { 2 - 12 } & 1 & 2 & 3 & 4 & 5 & 6 & 7 & 8 & 9 & 10 \\
\hline & 25 & 0 & 0 & 0 & 0 & 0 & 0 & 0 & 0 & 0 \\
\hline 1 & 25 & 25 & 0 & 0 & 0 & 0 & 0 & 0 & 0 & 0 \\
\hline 2 & 25 & 25 & 25 & 25 & 0 & 0 & 0 & 0 & 0 & 0 \\
\hline 3 & 25 & 25 & 25 & 25 & 25 & 25 & 25 & 0 & 0 & 0 \\
\hline 4 & 25 & 25 & 25 & 25 & 25 & 25 & 25 & 25 & 25 & 25 \\
\hline 5 & 25 &
\end{tabular}

Table 8 Parameters of cross traffic (Pattern $6 ; A=75$ Mbps)

\begin{tabular}{|c|c|c|c|c|c|c|c|c|c|c|}
\hline Case & \multicolumn{10}{|c|}{ Sending rate of cross traffic (Mbps) } \\
\cline { 2 - 12 } & \multicolumn{10}{|c|}{ Relay node $(h)$} \\
\cline { 2 - 12 } & 1 & 2 & 3 & 4 & 5 & 6 & 7 & 8 & 9 & 10 \\
\hline 1 & 25 & 0 & 0 & 0 & 0 & 0 & 0 & 0 & 0 & 0 \\
\hline 2 & 25 & 12.5 & 0 & 0 & 0 & 0 & 0 & 0 & 0 & 0 \\
\hline 3 & 12.5 & 25 & 12.5 & 12.5 & 0 & 0 & 0 & 0 & 0 & 0 \\
\hline 4 & 12.5 & 12.5 & 12.5 & 25 & 12.5 & 12.5 & 12.5 & 0 & 0 & 0 \\
\hline 5 & 12.5 & 12.5 & 12.5 & 12.5 & 25 & 12.5 & 12.5 & 12.5 & 12.5 & 12.5 \\
\hline
\end{tabular}

gorithm of Pathload is more effective than searching within a small search range used in the rate adjustment algorithm of the proposed method. However, it is difficult for general available bandwidth estimation methods to determine whether there is a large difference between the primary available bandwidth $\left(A^{1 s t}\right)$ and the estimated available bandwidth. The issues involved in such cases have been left to future work.

\section{Conclusions}

In this paper, we proposed an available bandwidth estimation method that is comprised of two functions for providing high accurate estimation and low network load performance. One function is the available bandwidth estimation function that directly calculates available bandwidth by using the end-to-end delay increase rate. The other function is the rate adjustment algorithm that adjusts the error between the actual available bandwidth and the available bandwidth calculated using the available bandwidth estimation function. From the simulation results, the primary available bandwidth of the proposed method was found to 


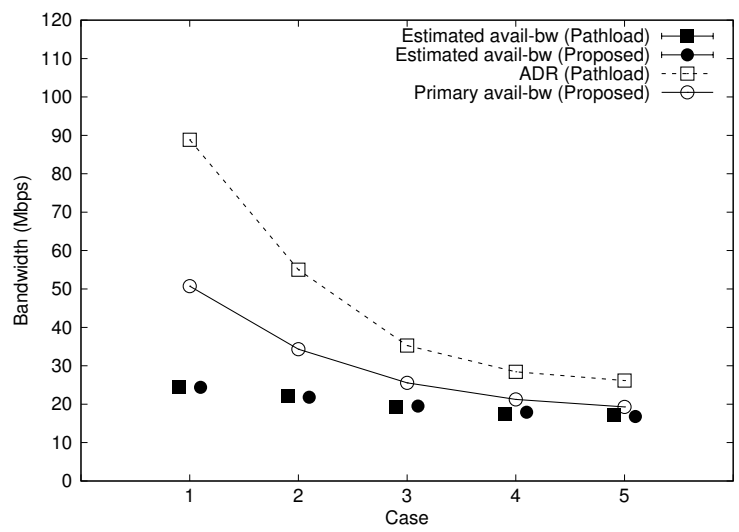

Fig. 6 Estimated avail-bw, ADR, and primary avail-bw (Pattern 1; $A=25$ Mbps)

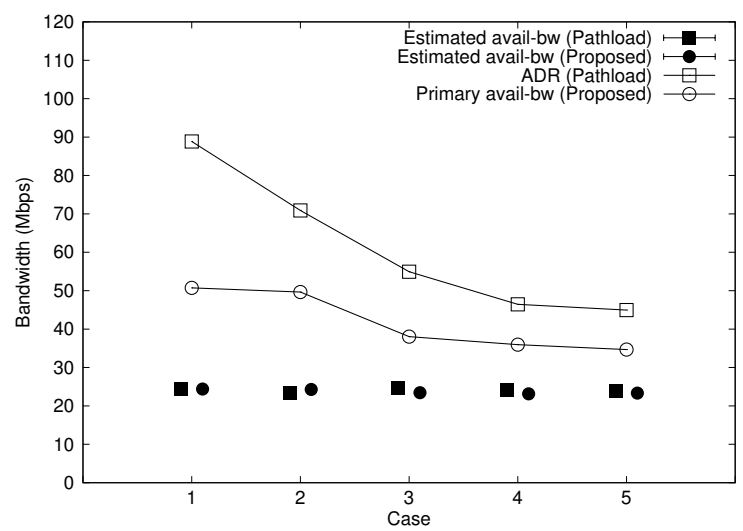

Fig. 8 Estimated avail-bw, ADR, and primary avail-bw (Pattern 3; $A=25$ Mbps)

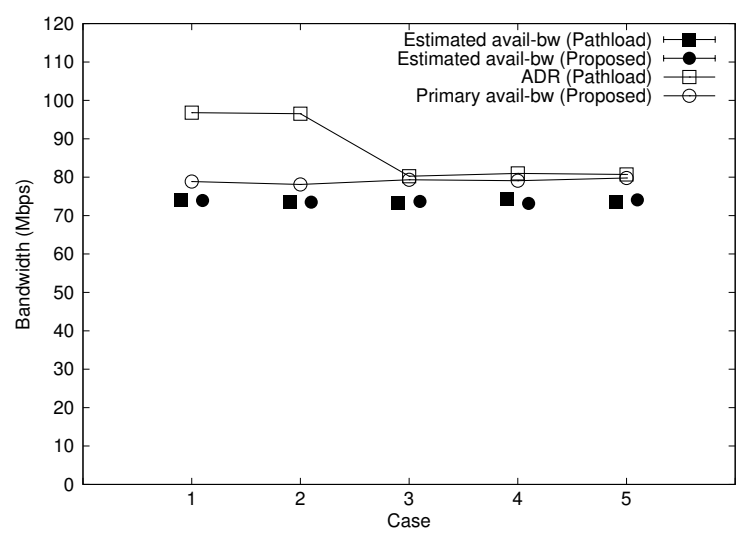

Fig. 10 Estimated avail-bw, ADR, and primary avail-bw (Pattern 5; $A=75$ Mbps)

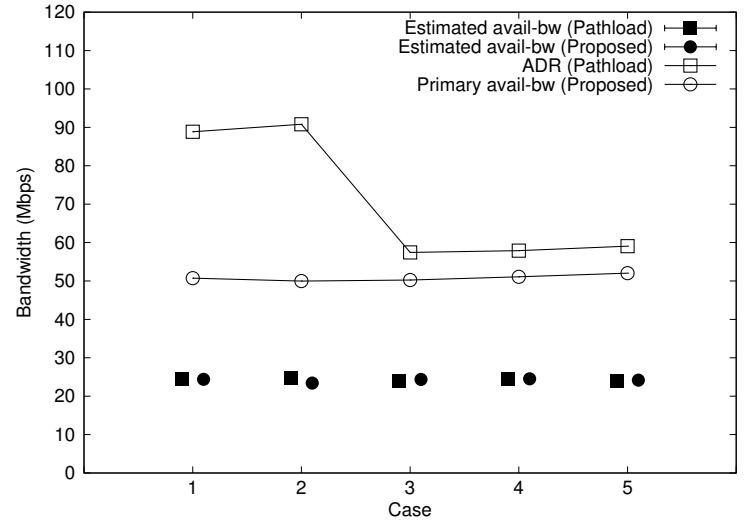

Fig. 7 Estimated avail-bw, ADR, and primary avail-bw (Pattern 2; $A=25 \mathrm{Mbps}$ )

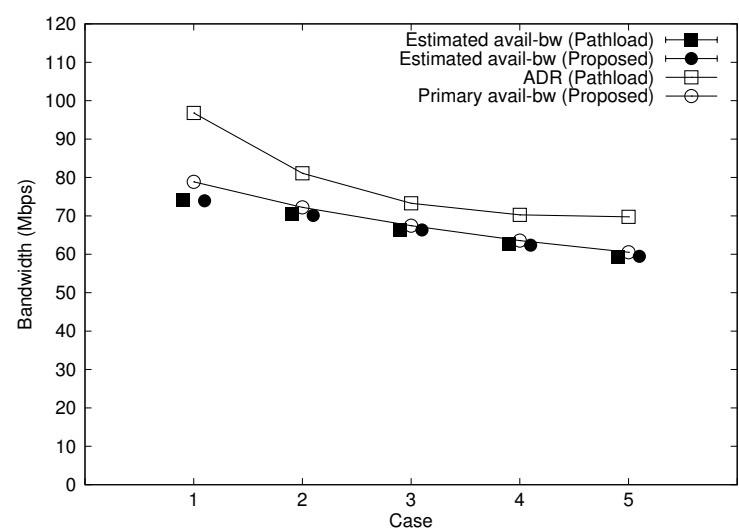

Fig. 9 Estimated avail-bw, ADR, and primary avail-bw (Pattern 4; $A=75 \mathrm{Mbps}$ )

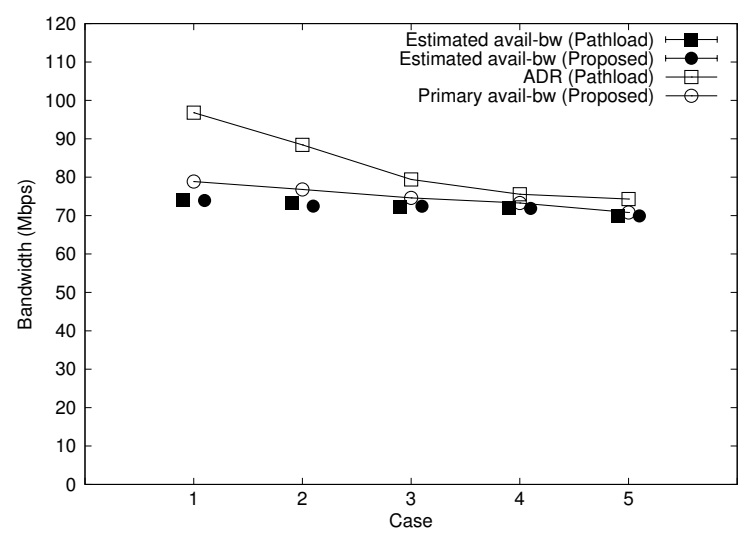

Fig. 11 Estimated avail-bw, ADR, and primary avail-bw (Pattern 6; $A=75 \mathrm{Mbps}$ ) 


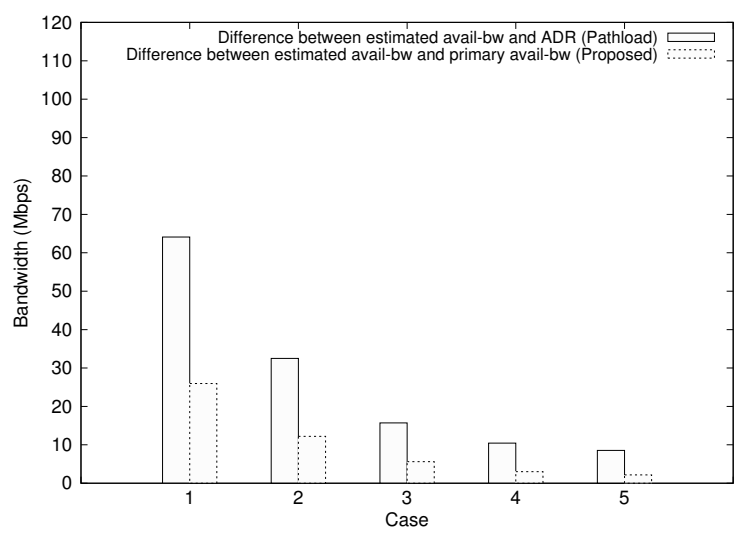

Fig. 12 Differences between estimated avail-bw and ADR and between estimated avail-bw and primary avail-bw (Pattern 1; $A=25$ Mbps)

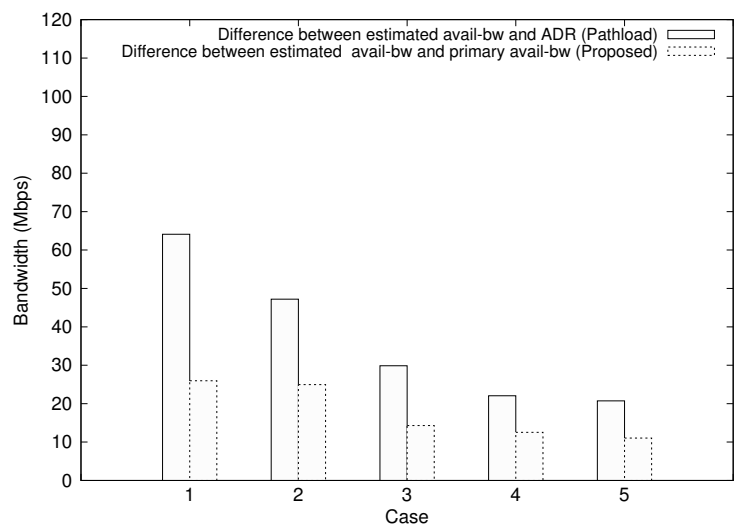

Fig. 14 Differences between estimated avail-bw and ADR and between estimated avail-bw and primary avail-bw (Pattern 3; $A=25$ Mbps)

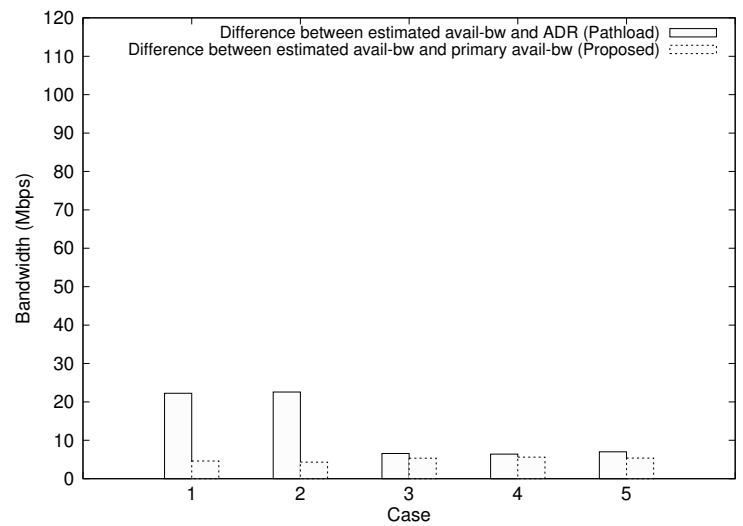

Fig. 16 Differences between estimated avail-bw and ADR and between estimated avail-bw and primary avail-bw (Pattern 5; $A=75$ Mbps)

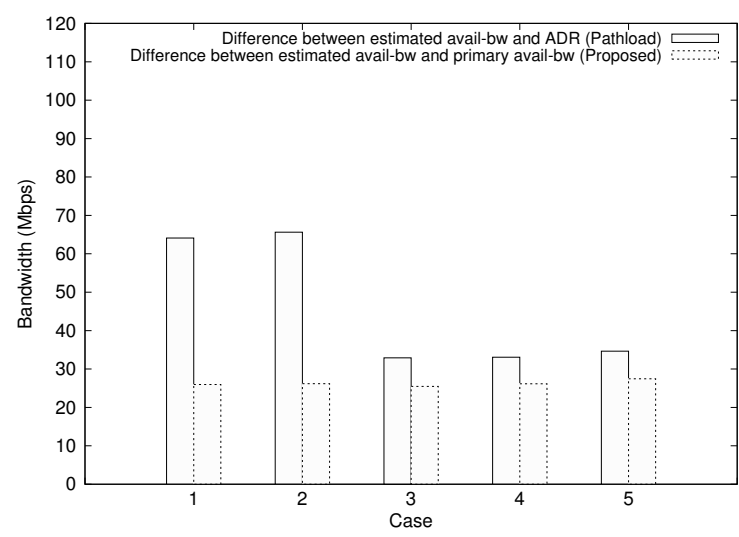

Fig. 13 Differences between estimated avail-bw and ADR and between estimated avail-bw and primary avail-bw (Pattern 2; $A=25 \mathrm{Mbps}$ )

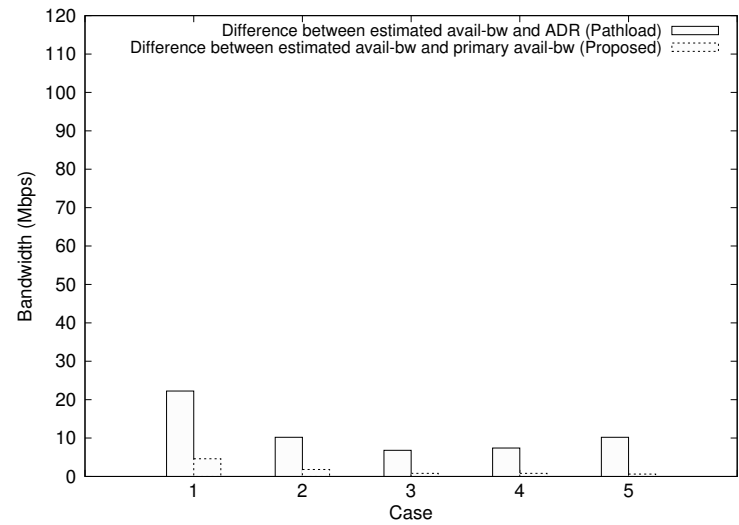

Fig. 15 Differences between estimated avail-bw and ADR and between estimated avail-bw and primary avail-bw (Pattern 4; $A=75 \mathrm{Mbps}$ )

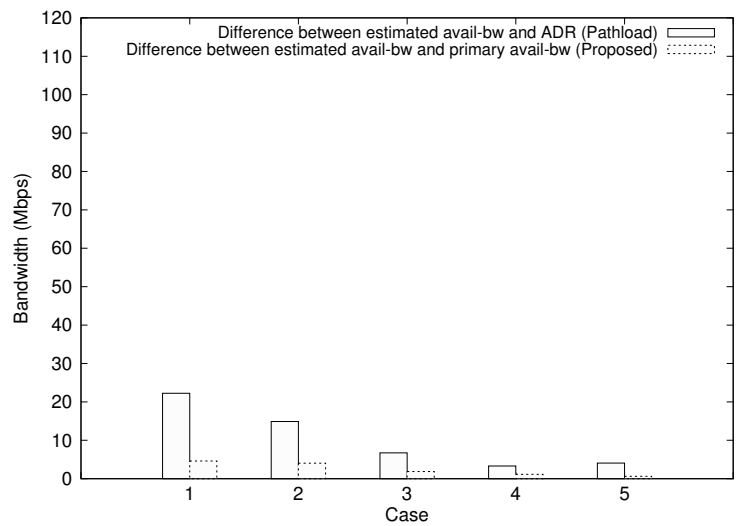

Fig. 17 Differences between estimated avail-bw and ADR and between estimated avail-bw and primary avail-bw (Pattern 6; $A=75 \mathrm{Mbps}$ )

Journal of Signal Processing, Vol. 22, No. 2, March 2018 


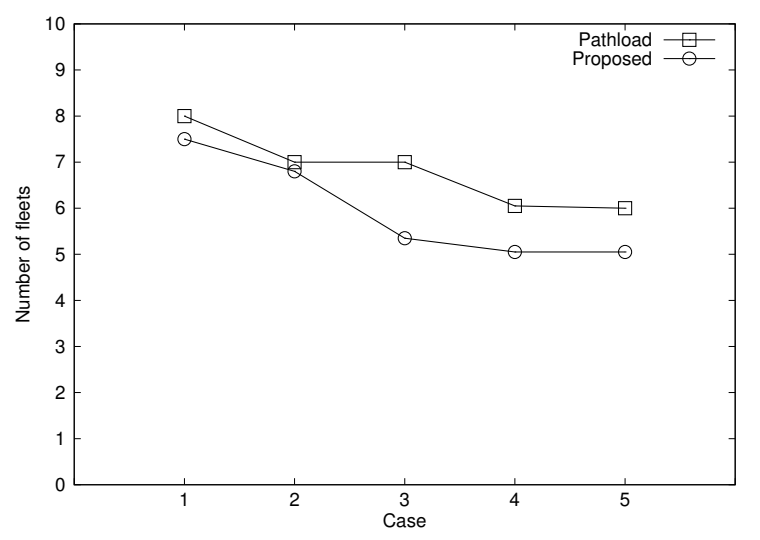

Fig. 18 Number of fleets (Pattern 1; $A=25 \mathrm{Mbps}$ )

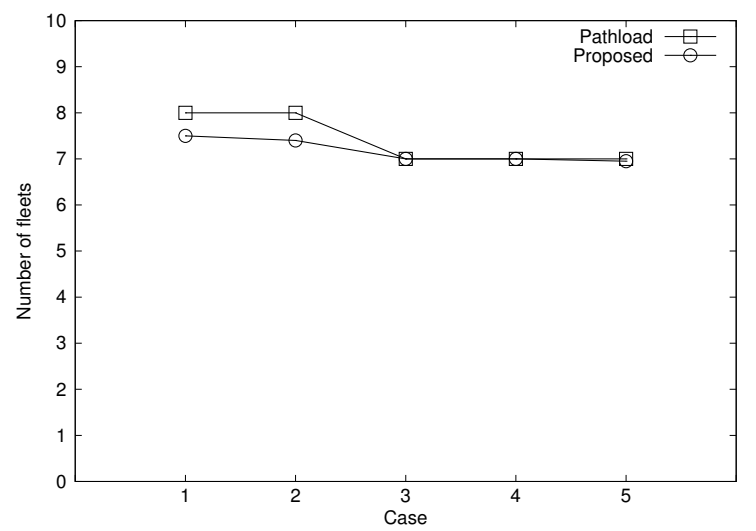

Fig. 20 Number of fleets (Pattern 3; $A=25 \mathrm{Mbps}$ )

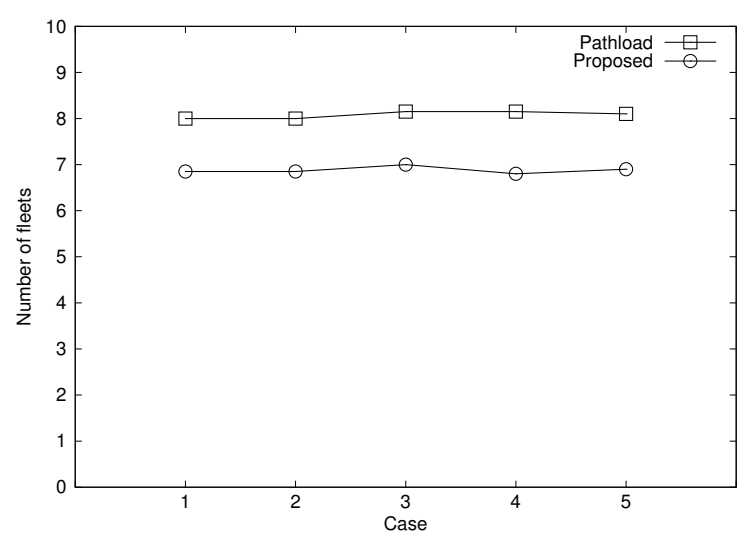

Fig. 22 Number of fleets (Pattern 5; $A=75 \mathrm{Mbps}$ )

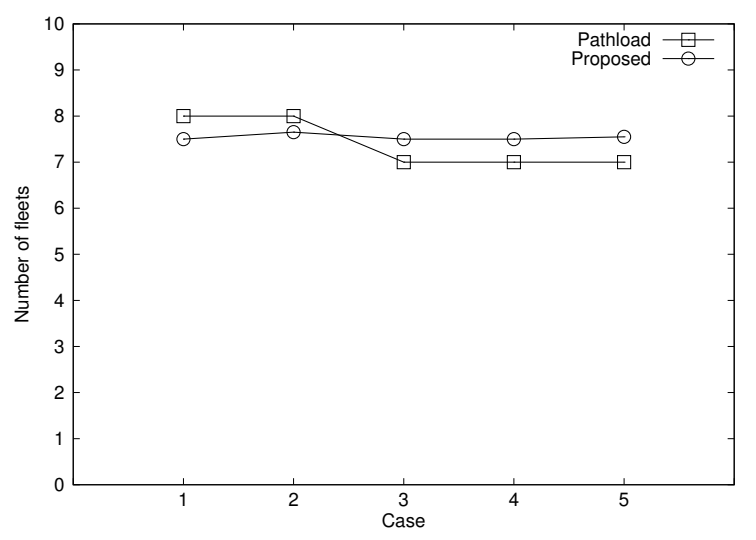

Fig. 19 Number of fleets (Pattern 2; $A=25 \mathrm{Mbps}$ )

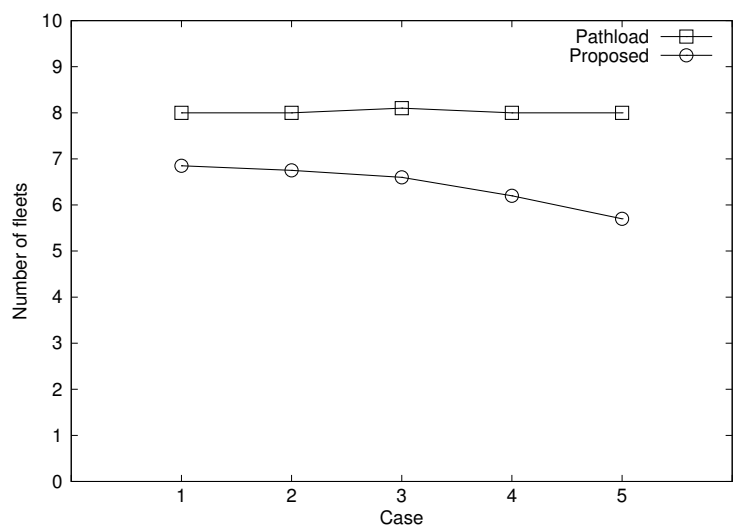

Fig. 21 Number of fleets (Pattern 4; $A=75 \mathrm{Mbps}$ )

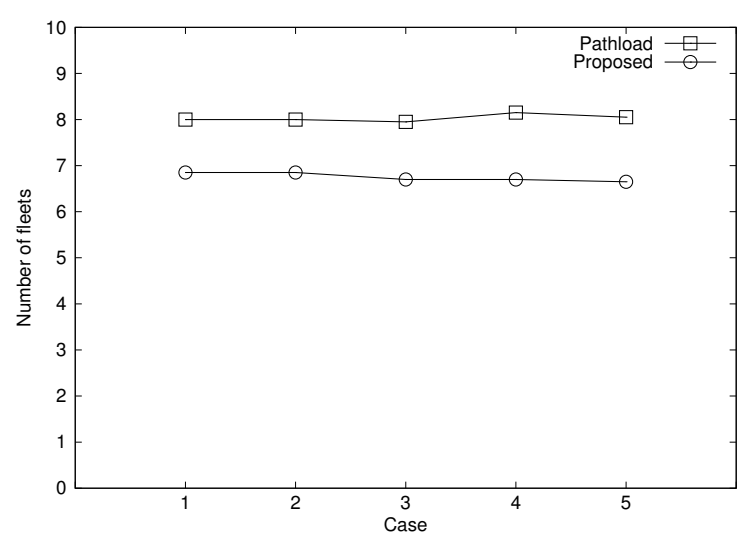

Fig. 23 Number of fleets (Pattern 6; $A=75 \mathrm{Mbps}$ ) 
be more accurate than the ADR of Pathload. In addition, when the parameters of the proposed method are allocated the same values as those of Pathload, the estimated available bandwidth of the proposed method is almost the same as that of Pathload. Moreover, the network load of the proposed method is smaller than that of Pathload except a few cases. Future work will include evaluations in terms of estimation accuracy and network load performance under various system parameters. In addition, we plan to present a new available bandwidth estimation method involving the measurement of end-to-end hop count because it is expected that information regarding end-to-end hop count further improves the estimation accuracy of available bandwidth.

\section{Acknowledgements}

This work was supported by the Japan Society for the Promotion of Science KAKENHI (Grant Number: 25870696; Principal Investigator: Masaki Hanada).

\section{References}

[1] C. Wu, B. Li and S. Zhao: Characterizing peer-to-peer streaming flows, IEEE Journal on Selected Areas in Communications, Vol. 25, No. 9, pp. 1612-1626, 2007.

[2] L. Favalli, M. Folli, A. Lombardo, D. Reforgiato and G. Schembra: A bandwidth-aware P2P platform for the transmission of multipoint multiple description video streams, Proc. of the Italian Networking Workshop 2009, 2009.

[3] M. Jain and C. Dovrolis: End-to-end available bandwidth: Measurement methodology, dynamics, and relation with TCP throughput, IEEE/ACM Transactions on Networking, Vol. 11, No. 4, pp. 537-549, August 2003.

[4] N. Hu and P. Steenkiste: Evaluation and characterization of available bandwidth probing techniques, IEEE Journal on Selected Areas in Communications, Vol. 21, No. 6, pp. 879-894, August 2003.

[5] V. J. Ribeiro, R. H. Riedi, R. G. Baraniuk, J. Navratil and L. Cottrell: PathChirp: Efficient available bandwidth estimation for network paths, Proc. of the Passive and Active Measurements Workshop, 2003.

[6] J. Sommers, P. Barford and W. Willinger: A proposed framework for calibration of available bandwidth estimation tools, Proc. of the 11th IEEE Symposium on Computers and Communications ISCC'06, pp. 709$718,2006$.

[7] E. Goldoni, G. Rossi and A. Torelli: Assolo, a new method for available bandwidth estimation, Proc. of the 4th International Conference on Internet Monitoring Protection ICIMP'09, pp. 130-136, May 2009.

[8] E. Goldoni and M. Schivi: End-to-end available bandwidth estimation tools, an experimental comparison, TMA 2010, Lecture Notes in Computer Science, Vol. 6003, pp. 171-182, 2010.
[9] G. Aceto, A. Botta, A. Pescape and M. D'Arienzo: Unified architecture for network measurement: The case of available bandwidth, Journal of Network and Computer Applications, Vol. 35, No. 5, pp. 1402-1414, 2012.

[10] L. Angrisani, S. D'Antonio, M. Esposito and M. Vardusi: Techniques for available bandwidth measurement in IP networks: A performance comparison. Elsevier Computer Networks, Vol. 50, No. 3, pp. 332-349, 2006.

[11] A. Shriram and J. Kaur: Empirical evaluation of techniques for measuring available bandwidth, Proc. of 26th IEEE International Conference on Computer Communications INFOCOM'07, pp. 2162-2170, 2007.

[12] J. Strauss, D. Katabi and F. Kaashoek: A measurement study of available bandwidth estimation tools, Proc. of the ACM SIGCOMM Internet Measurement Conference IMC'03, pp. 39-44, October 2003.

[13] C. Dovrolis and M. Jain: Pathload, https://www. cc.gatech.edu/ dovrolis/bw-est/pathload.html, 2006.

[14] K. Lai and M. Baker: Measuring link bandwidths using a deterministic model of packet delay, Proc. of the ACM SIGCOMM 2000, pp. 283-294, September 2000.

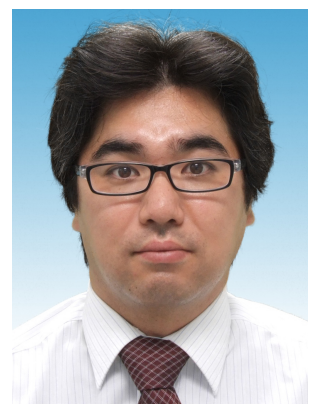

Masaki Hanada received his B.E. degree in Resources Engineering from Waseda University in 1996, and M.S. and D.S. degrees in Global Information and Telecommunication Studies from Waseda University, Japan in 2003 and 2007, respectively. He is an Associate Professor in the Department of Information Systems, Tokyo University of Information Sciences. His research interests include traffic control and resource management in communication networks. He is a member of the RISP, IEEE and IEICE.

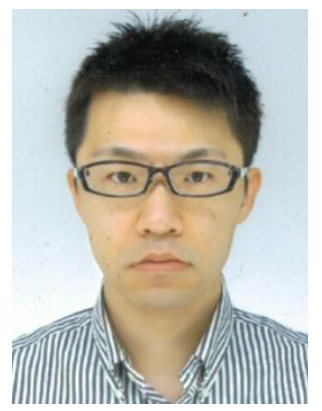

Hidehiro Kanemitsu received his B.S. degree in Science from Waseda University, Japan in 2002 and M.S. and D.S. degrees in Global Information and Telecommunication Studies from Waseda University, Japan in 2006 and 2012, respectively. His research interests include parallel and distributed computing, grid, peer-to-peer computing, and web service technology. He is currently an Assistant Professor at the Global Education Center, Waseda University, Japan. He is a member of the RISP, IEEE and IEICE.

(Received August 15, 2017; revised November 1, 2017) 